Upon an anvil, a disk of paper, of three inches in diameter, was laid, covered with pulverized sugar. Over the sugar was placed another similar disk covered with pulverized nitre. A bar of iron, rather wider than the disks at a welding heat, was then held over them, and subjected to a blow from a sledge. An explosion, with a report like that of a cannon, ensued.

Instructed by the facts and considerations above stated, it is inferred that the explosions which contributed to extend the conflagration in New York, as above memioned, arose from the reaction of the nitre with the combustible merchandise with which it was surrounded. It is presumed that as soon as the fire reached any of the gunny bags, it must have run rapidly through the whole pile, by means of the interstices necessarily existing between them, the nitre with which they were embued causing them to deflagrate. Much of the salt being thus brought to the temperature of fusion, it must have run about the floor, reached the combustibles, and soon found its way to the next story through the scuttles which were open. All the floors must have been rapidly destroyed by the consequent deflagration, far exceeding in activity any ordinary combustion. Meanwhile, the nitre being all liquified and collected in the cellar in a state of incandescence, and the merchandise conglomerated by the fusion of sugar and shell lac, aided by the molasses, the weight, the liquidity, and temperature, must have produced all the conditions requisite to intense detonations. The floors having been consumed, the store must have been equivalent to an enormous crucible of twenty feet by ninety, at the bottom of which were nearly three hundred thousand pounds of nitre, superficially heated far above the temperature producible by any furnace so as to convert the reagents into nascent aeriform matter under a pressure of half a million of pounds. The intense reaction, however, would not permit of durable contact. At each impact, the whole mass must have been thrown up explosively, and hence the successive detonations. But the chemical reaction, the heat, and the height of the fall, growing with their growth, and strengthening with their strength, the last elevation was succeeded by the thundering report and stupendous explosion, of which it has been an object to afford a satisfactory explanation.*

\title{
COMMITTEE ON SCIENCE AND THE ARTS.
}

\section{Report on the Explosion of a Steam Boiler.}

The Committee on Science and the Arts, constituted by the Franklin Institute of the State of Pennsylvania for the promotion of the Mechanic Arts, by whom were appointed a sub-commitlee to examine into the cause of the explosion of a stationary engine in Dillwyn street, Philadelphia, on the 20th day of March, 1848,

Report-

That they examined the fragments of the boiler, and found that it had been cylindrical, 14 feet in length, and 18 inches in

* In a sho: time a more circumstantial account of Dr. Hare's experiments and inferences respecting the subjects of the above communication will be published. 
diameter, made of iron $\frac{1}{3}$ inch thick, and apparently not of very good quality. The rupture had taken place nearly in the middle of its length, and presented the appearance of a clean cut around the boiler, just at the edge of one of the sheets of which it was composed, and exactly along the line which must have been followed by the caulking-tool. There was no tearing of the body of the sheet, and no irregularity in the line of fracture, except for about $\frac{1}{2}$ inch in length at the lowest part, where there were some slight irregularities, as though the iron had torn there, after the rest had given way. Upon a closer inspection the mark of the caulking tool was plainly visible, and it was seen to have cut into the iron, sometimes to a considerable depth. The committee have no donbt that this carelessness in caulking the boiler inaterially weakened it, and thus determined the line of the fracture. It is proper to remark that it was stated to the committee, that the cylinder was not constructed for a boiler, but had been used as a condenser, and was bought by its late proprietor at second hand, and by him applied as a boiler.

The boiler had been placed in the second story of a frame building on the east side of Dillwyn street, and in the rear of the lots attached to the houses on Third sireet, and was used by a Mr. Reeve, to drive a small engine for the purpose of cutting tobacco. The boiler lay east and west, slightly inclining downwards to the east, which was the fire end. The fire-way extended from the front, backwards, be neath the boiler, and was then returned by an outside flue, which lay above the ordinary water-level of the boiler. A blower was attached to the engine; it appeared to have been recently added, and gentlemen who were familiar with the premises, asserted that there was nothing of the kind when the boiler was first erected. The chimney stack being destroyed, the committee could not determine whether any defect had existed in the draft.

The westward or back part of the boiler had passed through the front of the house, and struck the dweiling on the opposite side of Dill wyn street, driving in the front wall. The fire end of the boiler passed across the whole lot between it and the houses in Third street, a distance of 112 feet, aud struck the edge of a doorway, in an 18 inch wall, which it destroyed. Both these projections indicate a great force of steam; and upon examination the committee found a distinctly marked water-line, showing that the depth of water at the point of fracture was only about 3 inches. There were, however, no conclusive marks of high heat on the iron.

Althongh the thickness of the iron had been reduced by the cutting of the caulking-tool, and althongh the iron did not appear to be of very good quality, yet the committee believe that it was capable, with proper care, of bearing with safety, any pressure necessary for the light work which the engine had to do. Assuming the iron to have been but $\frac{1}{16}$ th inch thick, and taking its tensile strength at 50,000 lbs per sq. inch, it would have been capable of resisting a strain in the direction in which fracture took place, of more than 45 atmospheres pressure. 
It is a little singular that the boiler should have given way in the direction in which, by theory, it is considerably the strongest. For a tearing strain in the direction of the axis of the boiler, the resistance would have been equivalent to but 25 atmospheres, $(347 \mathrm{lbs}$. per square inch,) if we take $50,000 \mathrm{lbs}$.

A very simple calculation will suffice to show that the pressure within the boiler at the moment of explosion was enormous. In fact, if we suppose the boiler lying quite horizontal, the projectile force was sufficient to carry the eastern fragment over 112 feet, while it fell 12 feet by the action of gravity, that is in 0.866 sec. 'The projectile force, therefore, gave to a mass of about $300 \mathrm{lbs}$, a velocity of 130 feet per second.

In the opinion of the committee, therefore, the explosion of this steam boiler was owing to an excessive pressure of steam, probably generated instantaneously by the admission of water to overheated metal, and the line of fracture was determined by the weakening of the iron at the junction of two of the plates, by the careless use of the caulking-tool.

By order of the Committee,

William Hamirton, Actuary.

Report on MM. DURand \& Pecquevr's process for manufacturing various articles from Leather.

The Committee on Science and the Arts, constituted by the Franklin Institute of the State of Pennsylvania for the promotion of the Mechanic Arts, to whom was referred for examination the process for manufacturing various articles from Leather, invented by MM. Durand \& Pecqueur, Paris,

\section{REPORT-}

That they have examined with much satisfaction the various articles which have been brought before them by Mr. Rabeau, manufactured in leather by the process invented by MM. Durand \& Pecqueur of Paris, of which process Mr. 'Rabeau is the patentee in the United States. They have likewise inspected the machine by which the various manufactures are produced. The patent is claimed for a method of manufacturing various hollow articles of leather without seams, such as fire-hose, sword, and bayonet scabbards, canteens, shot pouches, cartridge boxes, military caps, boots and shoes, cigar, and spectacle cases, \&c., \&c. The principle of the method is to divide the leather in a noistened state, in the direction of the plane of its length and breadth, making in the case of fire-hose, a slit through its entire length, leaving a border on both edges of the strip uncut. This is performed by means of a short knife at the end of a steel rod to which an alternate lateral motion is communicated by a peculiar mechanism; and this operation is performed witl so much accuracy, that the slit is made directly through the centre of the strip of leather, leaving the two sides everywhere of the same thickness, supposing the original strip to be of a uniform thickness. In the case of sword 